\title{
L-arginine-nitric oxide pathway and oxidative stress in plasma and platelets of patients with pre-eclampsia
}

\author{
Adriana ML Pimentel ${ }^{1}$, Natália R Pereira ${ }^{1}$, Cristiane A Costa ${ }^{1}$, Giovanni E Mann ${ }^{2}$, Viviane SC Cordeiro ${ }^{1}$, \\ Roberto $S$ de Moura ${ }^{1}$, Tatiana MC Brunini ${ }^{1}$, Antônio Cláudio Mendes-Ribeiro ${ }^{1}$ and Ângela C Resende ${ }^{1}$
}

Pre-eclampsia (PE), a syndrome of pregnancy-induced hypertension, continues to be a leading cause of maternal and fetal morbidity and mortality. The aim of this study was to investigate whether changes in oxidative status are correlated with alterations in the L-arginine-nitric oxide pathway and platelet aggregation in PE. Plasma and platelets from women with PE $(n=24)$ or normotensive pregnancy (NP, $n=27$ ) recruited in the third trimester of gestation were used to measure oxidative damage assessed by protein carbonyl content, antioxidant activities of superoxide dismutase (SOD), catalase (CAT) and nitrite levels. Transport of $\mathrm{L}-\left[{ }^{3} \mathrm{H}\right]$-arginine, as well as the activities of the nitric oxide (NO) synthase (eNOS and inducible NO synthase (iNOS)) and platelet aggregation, were also evaluated. Plasma nitrite levels and the activities of SOD and CAT were reduced in PE (5.2 $\pm 2.7,3.4 \pm 0.8,0.3 \pm 0.4$, respectively, $P<0.05)$ compared with NP $(8.7 \pm 2.3,6.7 \pm 3.1,1.0 \pm 0.5$, respectively), whereas protein carbonyl content and L-arginine levels were not significantly different between PE and NP groups. In platelets, L-arginine transport was reduced in PE $(19.2 \pm 10.5, P<0.05)$ compared with NP $(62.0 \pm 31.1)$, whereas the NOS activity, eNOS and iNOS expression, nitrite levels and platelet aggregation were unaffected. Protein carbonyl content was increased, and CAT activity was reduced in platelets from PE $(0.03 \pm 0.02,0.55 \pm 0.30$, respectively, $P<0.05)$, compared with NP $(0.005 \pm 0.005,1.01 \pm 0.36$, respectively). The data suggest that a systemic impairment of antioxidant defense mechanisms is associated with decreased plasma nitrite levels, which may contribute to hypertension in PE. Oxidative stress may contribute to the reduced influx of L-arginine in platelets. Compensatory mechanisms may contribute to the maintenance of NO production and its modulatory role on platelet function.

Hypertension Research (2013) 36, 783-788; doi:10.1038/hr.2013.34; published online 11 April 2013

Keywords: L-arginine; nitric oxide; oxidative stress; platelet aggregation; pregnancy

\section{INTRODUCTION}

Pre-eclampsia (PE) is a hypertensive pregnancy-related disorder and a major cause of neonatal and fetal morbidity and mortality. This syndrome is characterized by hypertension, proteinuria and edema that can be reversed after delivery of the placenta. ${ }^{1}$ The current consensus is that this disease leads to systemic inflammation, endothelial dysfunction, metabolic and coagulation disorders, and an imbalance between vasoconstrictor and vasodilator agents. ${ }^{2-4}$

The dysfunction of the maternal vascular endothelium has been reported to have a central role in $\mathrm{PE}^{5}$ This dysfunction manifests as enhanced formation of factors such as endothelin, reactive oxygen species (ROS) and augmented vascular sensitivity to angiotensin II. ${ }^{6}$ The PE syndrome may also be evident as decreased formation of vasodilators such as nitric oxide (NO) and prostacyclin., ${ }^{7,8}$ Taken together, these alterations cause hypertension by impairing renal pressure natriuresis and increasing total peripheral resistance. $^{8}$
Oxidative stress is now recognized to have a central role in the pathophysiology of many different disorders, including complications of pregnancy. Oxidative stress arises when the production of ROS overwhelms the intrinsic antioxidant defenses. ${ }^{5,9}$ ROS, such as superoxide and hydrogen peroxide, are important intracellular and intercellular second messengers that modulate signaling pathways and maintain the cell in homeostasis with its immediate environment. At higher levels, they can cause indiscriminate damage to biological molecules, leading to loss-of-function and even cell death. ${ }^{9}$ ROS are generated by placental hypoxia and reperfusion and have been suggested as contributors to the uteroplacental endothelial dysfunction in $\mathrm{PE}^{4,7,10}$ and platelet activation. ${ }^{11}$ Oxidative stress results in endothelial dysfunction, either by direct action on the vasculature or through reduction in the bioavailability of vasoactive mediators, such as NO. ${ }^{8}$

$\mathrm{NO}$ is one of the most important vascular signaling molecules, and it has other important functions, such as reduction of platelet

${ }^{1}$ Department of Pharmacology, Institute of Biology, Rio de Janeiro State University, Rio de Janeiro, Brazil and ${ }^{2}$ Cardiovascular Division, British Heart Foundation of Research Excellence, School of Medicine, King's College London, London, UK

Correspondence: Dr ÂC Resende, Departamento de Farmacologia e Psicobiologia, IB, Universidade do Estado do Rio de Janeiro, Av. 28 de Setembro, 87, Rio de Janeiro 20551 030, Brazil.

E-mail: angelacr@uerj.br or angelacr@hotmail.com

Received 13 September 2012; revised 3 January 2013; accepted 31 January 2013; published online 11 April 2013 
sensitivity to pro-aggregating agents. ${ }^{12}$ In human platelets, $\mathrm{NO}$ is formed from the cationic amino-acid L-arginine by inducible NO synthase (iNOS) and constitutive NOS (eNOS). ${ }^{12}$ Extracellular $\mathrm{L}$-arginine transport into human platelets is mediated by system $\mathrm{y}^{+} \mathrm{L}$, which modulates NO production in these cells. ${ }^{13}$ It is well known that patients with $\mathrm{PE}$ are at a higher risk of developing thrombotic events and increasing evidence has highlighted an important role for the L-arginine-NO pathway in the atherothrombotic process of PE. ${ }^{14,15}$ Recent studies have demonstrated that asymmetric dimethyl-L-arginine levels, an endogenous inhibitor of NO synthesis, ${ }^{16,17}$ is increased in the plasma of pregnant women with $\mathrm{PE}$ and that platelet sensitivity to $\mathrm{L}$-arginine is decreased in PE women. ${ }^{18}$ These findings may contribute to hypercoagulability in the disease.

As ROS have been proposed as an important contributor to endothelial dysfunction associated with $\mathrm{PE}^{8}$ and platelet activation, ${ }^{11}$ in this study we have evaluated whether oxidative stress is associated with changes in the L-arginine-NO pathway and platelet aggregation in $\mathrm{PE}$.

\section{METHODS}

\section{Subjects}

A total of 24 pregnant women aged between 18 and 35 years with PE from the Outpatients Maternity/Rio de Janeiro State University and 27 age-matched normal pregnancy (NP) volunteers participated in the study (Table 1). Most of the women included in this study were diagnosed with late-onset PE ( $>34$ weeks). Only one woman from the control group and one from the PE group were diagnosed at 33 weeks. PE participants belonged to the restricting subtype according to the International Society for the Study of Hypertension in Pregnancy. The exclusion criteria were the following: prior toxemia, diabetes mellitus, previous history of arterial hypertension, chronic renal and heart failure, twin pregnancy, ectopic pregnancy, hydatidiform mole, fetal hydrops, platelet dysfunction, coagulation disorders and chronic use of antiplatelet drugs in the current pregnancy. The investigation conformed to the principles outlined in the Declaration of Helsinki as revised in 2001. The Pedro Ernesto Hospital Ethical Committee, Rio de Janeiro State University (1730-CEP/ HUPE-CAAE: 0018.0.228.000-07), approved this work. Signed informed consent from the participants was obtained.

\section{Blood collection and preparative procedures}

The venous blood was anticoagulated with a citric acid-dextrose anticoagulant solution $(73.7 \mathrm{~mm}$ citric acid, $85.9 \mathrm{~mm}$ trisodium citrate and $111 \mathrm{~mm}$ dextrose, $\mathrm{pH}$ 4.5). As described previously, ${ }^{19}$ platelet-rich plasma (PRP), obtained by centrifugation of whole blood at $200 \times g$ for $15 \mathrm{~min}$, was centrifuged at $900 \times g$ for $10 \mathrm{~min}$. The pellet was resuspended in Kreb's buffer $\left(\mathrm{mmoll}^{-1} ; 119 \mathrm{NaCl}\right.$, $4.6 \mathrm{KCl}, 1.5 \mathrm{CaCl}_{2}, 1.2 \mathrm{NaH}_{2} \mathrm{PO}_{4}, 1.2 \mathrm{MgCl}_{2}, 15 \mathrm{NaHCO}_{3}$, and 11 glucose,

Table 1 Clinical and laboratorial data

\begin{tabular}{lcc}
\hline & $N P$ & $P E$ \\
\hline Age (years) & $24.7 \pm 5.2$ & $25.18 \pm 4.8$ \\
Gestational age (weeks) & $37.7 \pm 2.3(33-41)$ & $36.1 \pm 1.5^{\mathrm{a}}(33-38)$ \\
Number of gestations & $2.3 \pm 1.2$ & $1.77 \pm 1.0$ \\
Parity & $1.25 \pm 1.02$ & $0.38 \pm 0.86^{\mathrm{a}}$ \\
SBP (mm Hg) & $109.4 \pm 13.4$ & $158.7 \pm 15.8^{\mathrm{a}}$ \\
DBP (mm Hg) & $70 \pm 8.6$ & $103.1 \pm 14.8^{\mathrm{a}}$ \\
MBP (mm Hg) & $83.1 \pm 9.8$ & $121.6 \pm 14.5^{\mathrm{a}}$ \\
Proteinuria $(\mathrm{g} \mathrm{per} \mathrm{24} \mathrm{h)}$ & Absent & 1.13 \\
Platelets $\left(10^{3} \mathrm{~mm}^{-3}\right)$ & $180.4 \pm 63.2$ & $217.8 \pm 52.4$ \\
L-arginine $(\mu \mathrm{M})$ & $97.8 \pm 25.5$ & $88.3 \pm 18.4$
\end{tabular}

Abbreviations: DBP, diastolic blood pressure; MBP, mean blood pressure; NP, normal pregnancy; PE, pre-eclampsia; SBP, systolic blood pressure.

Data are means \pm s.d., $n=27$ for NP and $n=24$ for PE.

asignificantly different from the NP group $(P<0.05)$.
$\mathrm{pH} 7$.4). This study examined cell preparations for contamination by other cells using a Beckman Coulter Counter (Beckman Coulter Inc., Hyogo, Japan) and light microscopy (Nikon, Tokyo, Japan). The patients and healthy volunteers who took part in the study were not the same in each experiment as, for ethical reasons, it would have been impossible to obtain the amount of blood required. No $>60 \mathrm{ml}$ of blood was collected from each woman.

\section{Measurement of L-arginine}

The amino-acid concentration was measured in plasma by the Diagnóstico Laboratoriais Especializados laboratory (Rio de Janeiro, RJ, Brazil) using highperformance liquid chromatography.

\section{$\mathrm{L}-\left[{ }^{3} \mathrm{H}\right]$-arginine influx in platelets}

Washed platelets $\left(1 \times 10^{9}\right.$ platelets $\left.\mathrm{ml}^{-1}\right)$ were incubated at $37^{\circ} \mathrm{C}$, and L- $[3 \mathrm{H}]-$ arginine influx $(1-50 \mu \mathrm{M})$ was measured over $5 \mathrm{~min}$. L-leucine $(10 \mathrm{~mm})$; a substrate for system $\mathrm{y}^{+} \mathrm{L}$, was used to resolve total L-arginine transport in platelets into system $\mathrm{y}^{+} \mathrm{L}$ and transport with diffusion kinetics. Transport was terminated by rapid centrifugation followed by lysis with Triton for $\beta$-scintillation counting. Platelets were counted using a Coulter counter. ${ }^{20}$

\section{Measurement of platelet NOS activity}

Basal NOS activity was determined from the conversion of $\mathrm{L}-[3 \mathrm{H}]$-arginine to $\mathrm{L}$ - $[3 \mathrm{H}]$-citrulline. ${ }^{21,22}$ Platelet suspensions $\left(1 \times 10^{8}\right.$ platelets $\left.\mathrm{ml}^{-1}\right)$ were incubated at $37^{\circ} \mathrm{C}$ in the presence of $\left.\mathrm{L}-{ }^{3} \mathrm{H}\right]$-arginine $\left(2 \mu \mathrm{Ci} \mathrm{ml}^{-1}\right)$ plus unlabeled L-arginine $(1 \mu \mathrm{M})$. All reactions were stopped by rapid centrifugation followed by two washes with Kreb's buffer. The platelet pellet was lysed with Triton and applied to a Dowex cation exchange resin column. The radioactivity was measured by liquid scintillation counting.

\section{Platelet aggregation protocol}

Platelet aggregation was evaluated in PRP by optical densitometry. Briefly, blood samples were anticoagulated with $3.8 \%$ trisodium sodium and centrifuged at $200 \times g$ for $15 \mathrm{~min}$ at room temperature. Platelet-poor plasma was obtained by centrifuging the leftover blood at $900 \times g$ for $10 \mathrm{~min}$. The platelet concentration in PRP was adjusted with platelet-poor plasma to a constant count of $1.5 \times 10^{8} \mathrm{ml}^{-1}$. Aggregation was induced by collagen $(2.5,5$ and $10 \mu \mathrm{g} \mathrm{ml}^{-1}$ ) and responses monitored for $5 \mathrm{~min}$ in a four-channel aggregometer (Chrono-Log, Havertown, PA, USA). Tests were performed at $37^{\circ} \mathrm{C}$ with a stirring speed of 900 r.p.m. Maximal aggregation was expressed in percentages. ${ }^{22}$

\section{Western blot analysis for eNOS and iNOS}

Platelets were isolated from the PRP by centrifugation, washed, then lysed with lysis buffer. Protein was quantified using BCA protein assay reagent (Pierce, Rockford, IL, USA). Samples containing $20 \mu \mathrm{g}$ protein were prepared in equal volumes of sample application buffer (NuPage LDS Sample Buffer, Invitrogen, Carlsbad, CA, USA), separated by $10 \%$ sodium dodecyl sulfate-polyacrylamide gel electrophoresis (Invitrogen), transferred to polyvinylidene difluoride membranes, and then immunoblotted with mouse monoclonal antibodies against human eNOS and iNOS (BD Transduction Laboratories, Franklin Lakes, NJ, USA) at a 1:2500 dilution. Gels were stained with Coomassie blue to check protein transfer. ${ }^{23}$ The blots were washed with phosphate buffer solution plus tween $(0.1 \%)$ and exposed to horseradish peroxidase-conjugated anti-rabbit immunoglobulin G secondary antibody (1:10 000) dissolved in 5\% (wt/vol) nonfat milk in buffer. We also incubated all membranes with $\beta$-tubulin antibody $(1: 1000)$ to avoid possible inconsistency in protein loading and/or transfer.

\section{Nitrite assay}

Nitrite $\left(\mathrm{NO}_{2}{ }^{-}\right)$levels in plasma were determined by a method based on the Griess reaction. ${ }^{24}$ A total of $100 \mu \mathrm{l}$ of sample was mixed with $100 \mu \mathrm{l}$ of Griess reagent ( $1 \%$ sulfanilamide in $5 \%$ phosphoric acid and $0.1 \%$ naphthylenediamide dihydrochloride in water) and incubated at room temperature for $10 \mathrm{~min}$ followed by measuring the absorbance in a plate reader at $550 \mathrm{~nm}$ (Bio-Rad Microplate Reader model 680, Hercules, CA, USA). Nitrite concentrations in the 
samples were determined from a standard curve generated by different concentrations of sodium nitrite.

\section{Superoxide dismutase (SOD) and catalase (CAT) activities}

Plasma and platelets were used to determine SOD and CAT activities. SOD activity was assayed by measuring the inhibition of adrenaline auto-oxidation as absorbance at $480 \mathrm{~nm}$. CAT activity was measured in terms of the rate of decrease in hydrogen peroxide at $240 \mathrm{~nm}$. The total protein content of each sample was determined by the Bradford method.

\section{Protein oxidation}

Oxidative damage to proteins was assessed by determination of carbonyl groups based on the reaction with dinitrophenylhydrazine (Sigma, St Louis, MO, USA), as previously described. ${ }^{25}$ Briefly, whole-cell proteins were precipitated by the addition of $20 \%$ trichloroacetic acid and redissolved in dinitrophenylhydrazine, and absorbance read at $370 \mathrm{~nm}$.

\section{Statistical analyses}

Data are expressed as the means \pm s.d. of measurements in $n$ different control subjects or PE patients. The normality of continuous variables was assessed using D'Agostino and Pearson omnibus normality test. Statistical significance was assessed using Mann-Whitney test for variables that did not follow a Gaussian distribution and unpaired $t$-test for normal distribution with equal variances, with $P<0.05$ considered significant. Data analyses were performed with GraphPad Prism version 5.0 software (GraphPad Software, San Diego, CA, USA).

\section{RESULTS}

Blood pressure

Figure 1 shows the increased systolic, diastolic and mean blood pressures of patients with PE compared with controls.

L-arginine influx in platelets

An analysis revealed that $\mathrm{L}$-arginine transport via the $\mathrm{y}^{+}{ }_{\mathrm{L}}$ system was decreased in patients with PE compared with controls (NP $62.00 \pm 31.06 n=8$, PE $19.23 \pm 10.54 n=9$; Figure 2a).

\section{Basal NOS activity in platelets and eNOS and iNOS protein expression}

Basal NOS activity, assaying the production of $\mathrm{L}-\left[{ }^{3} \mathrm{H}\right]$-citrulline from L- $\left[{ }^{3} \mathrm{H}\right]$-arginine, was not different in platelets from patients with PE compared with control pregnancies (NP $0.1163 \pm 0.0636 n=8$, $\mathrm{PE} 0.1288 \pm 0.0516 n=8$; Figure 2b). Furthermore, $\mathrm{PE}$ was not associated with changes in either eNOS (NP 6.660 $\pm 0.266 n=3$, PE $5.792 \pm 1.180 n=5$ ) and iNOS (NP $4.323 \pm 0.355 n=3$, PE $3.724 \pm 0.867 n=5$ ) expression in platelets (Figure $2 \mathrm{c}$ ).

\section{Platelet aggregation}

A dose-related effect was observed in platelet aggregation assays (\%), induced by increasing concentrations of fibrillar collagen $(2.5,5$ and $10 \mu \mathrm{g} \mathrm{ml}^{-1}$ ) in PRP. However, no difference was observed in platelet aggregation from patients with PE $(n=10)$ compared with controls $(n=8)$ at all collagen concentrations $\left(2.5 \mu \mathrm{g} \mathrm{m}^{-1} \mathrm{NP} 71.00 \pm 13.62\right.$, PE $57.00 \pm 19.92 ; 5 \mu \mathrm{g} \mathrm{ml}^{-1}$ NP $72.25 \pm 10.90$, PE $67.10 \pm 17.99$; $10 \mu \mathrm{g} \mathrm{ml}^{-1} \mathrm{NP} 76.38 \pm 11.49$, PE $74.60 \pm 16.04$; Figure 3).

\section{Platelet and plasma carbonyl content as an index of oxidative} damage

Plasma carbonyl content was not significantly different in the plasma of PE compared with control patients (NP $2.245 \pm 0.811 n=4$, PE $2.530 \pm 1.360 n=6$; Figure 4a). In contrast, intraplatelet carbonyl content was increased in platelets from PE patients compared with
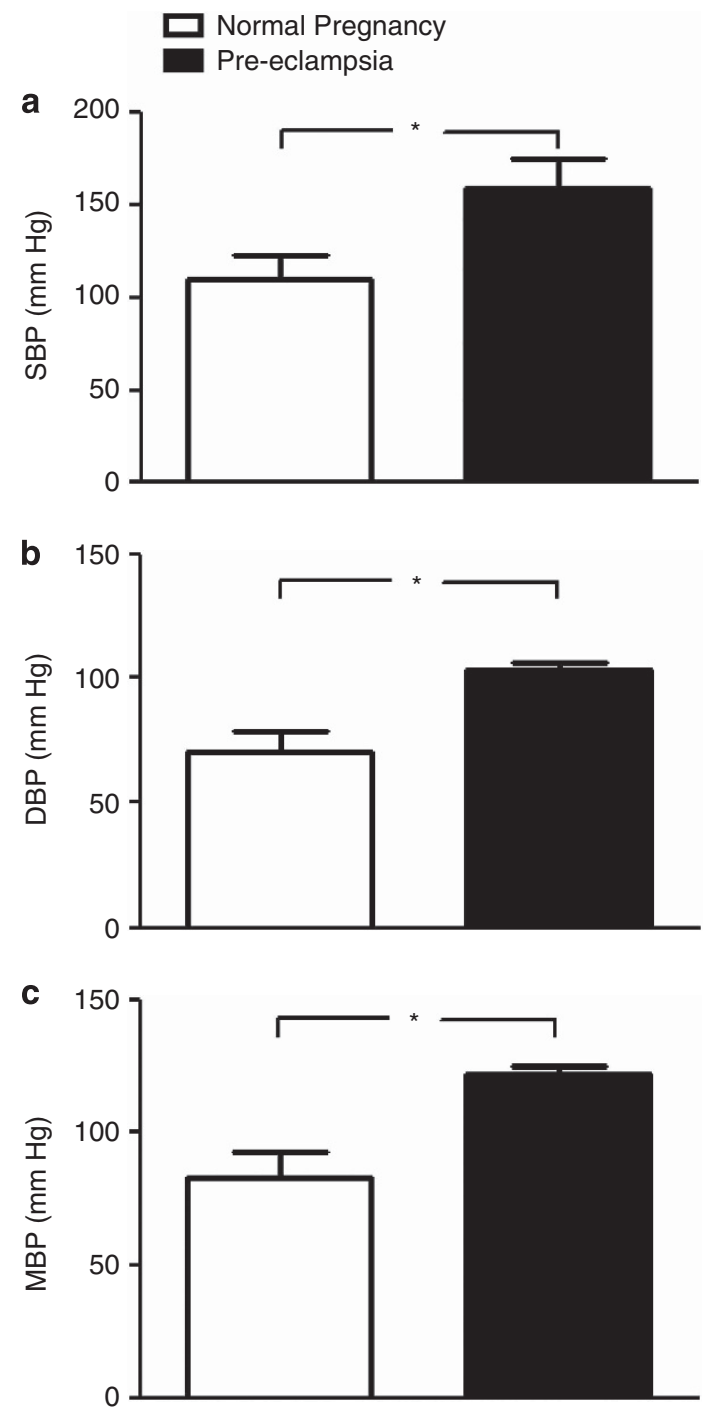

Figure 1 (a) Systolic blood pressure (SBP), (b) diastolic blood pressure (DBP), (c) mean blood pressure (MBP) of normal pregnancy (NP) and preeclampsia (PE) patients (NP $n=27$ and PE $n=24$ ). Values denote means \pm s.d. of the mean. ${ }^{*} P<0.05$

controls (NP $0.00505 \pm 0.00542 n=6$, PE $0.02712 \pm 0.02289 n=5$; Figure $4 \mathrm{~b})$.

\section{Platelet and plasma nitrite content}

Nitrite levels were diminished in the plasma of patients with PE when compared with controls (NP 8.68 $\pm 2.27 n=6$, PE 5.16 $\pm 2.66 n=5$; Figure 4c) but not different in platelets from PE or control patients (NP 24.46 $\pm 13.44 n=10$, PE $22.59 \pm 6.99 n=10$; Figure 4d).

Platelet and plasma antioxidant enzyme activities (SOD and CAT) SOD and CAT activities in plasma (Figures $5 \mathrm{a}$ and c) were decreased in patients with $\mathrm{PE}$ ( $n=6$ for each enzyme) when compared with controls ( $n=6$ for each enzyme). CAT activity in platelets was decreased in patients with $\mathrm{PE}(n=7)$ when compared with controls $(n=10)$ but no difference was observed in platelet SOD activity between groups ( $n=8$ for each group; Figures $5 \mathrm{~b}$ and $d$ ). 

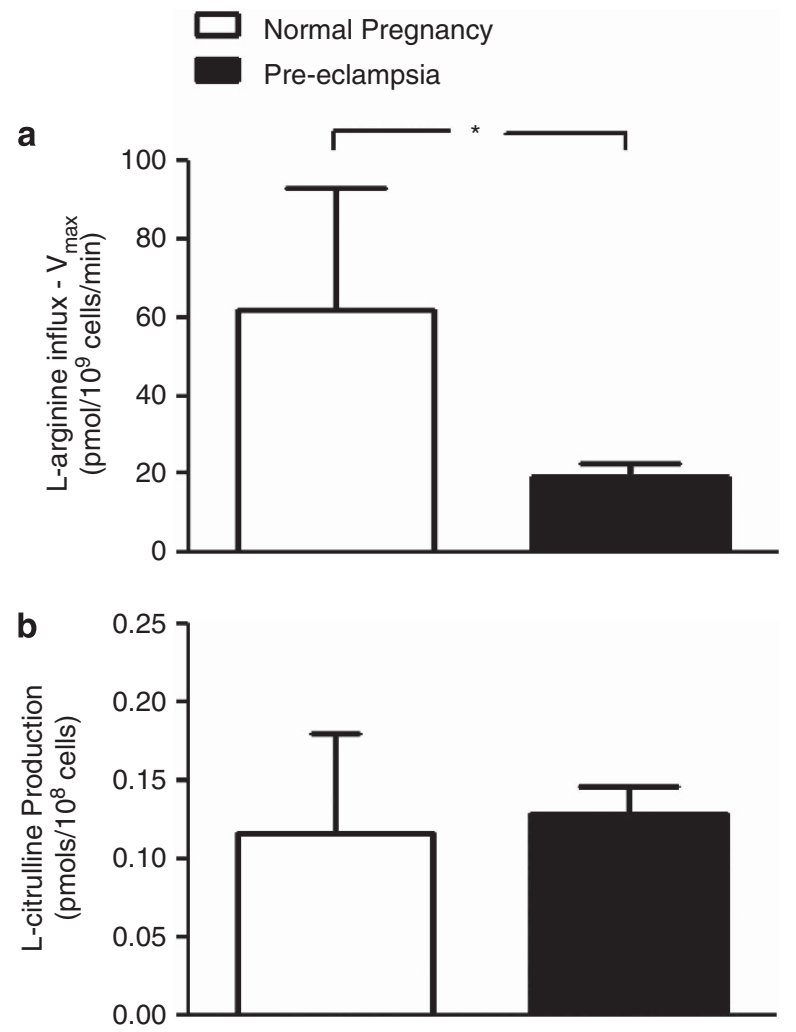

C

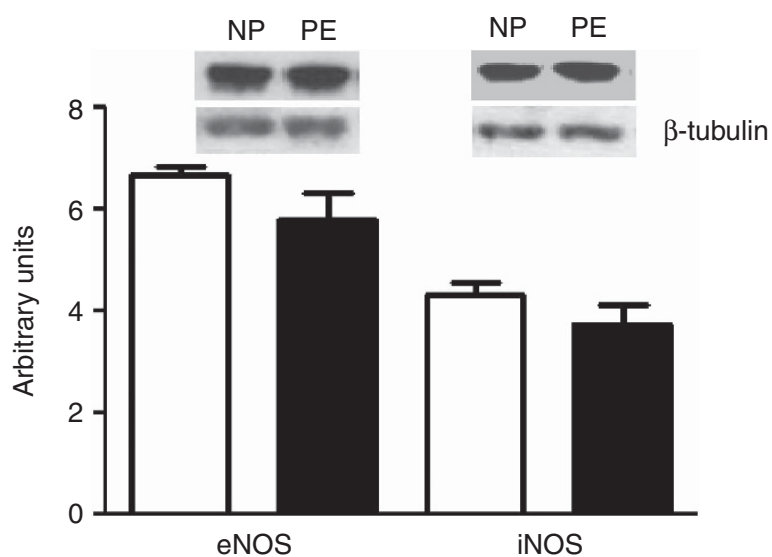

Figure 2 (a) L-arginine influx-Vmax (normal pregnancy (NP) $n=8$ and preeclampsia (PE) $n=9$ ), (b) nitric oxide synthase (NOS) activity (NP $n=8$ and PE $n=8$ ) and (c) expression of eNOS and inducible NO synthase (iNOS; NP $n=3$ and PE $n=5$ ) were analyzed in platelets from NP and PE patients. Values denote means \pm s.d. of the mean. ${ }^{*} P<0.05$.

\section{Measurement of L-arginine}

Plasma levels of L-arginine were not significantly different in $\mathrm{PE}$ patients when compared with controls (NP 97.86 $\pm 25.50 n=7$, PE $88.33 \pm 18.42 n=6$; Table 1).

\section{DISCUSSION}

This study highlights that PE-induced oxidative stress may contribute to physical and structural changes of the platelet membrane, thus leading to reduced platelet L-arginine transport. However, no changes were detected in $\mathrm{NO}$ synthesis or platelet aggregation.

This study demonstrates for the first time that the transport of $\mathrm{L}$-arginine via system $\mathrm{y}^{+} \mathrm{L}$ is reduced in patients with PE compared

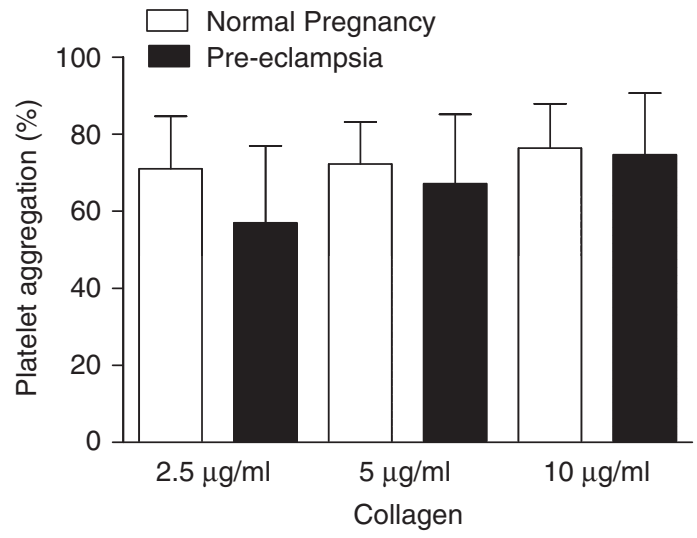

Figure 3 Platelet aggregation (\%) induced by different concentrations of fibrillar collagen 2.5, 5 and $10 \mu \mathrm{g} \mathrm{ml}^{-1}$ in platelet-rich plasma (PRP) from pre-eclampsia (PE) and normal pregnancy (NP; $n=8)$. Values denote means \pm s.d. of the mean.
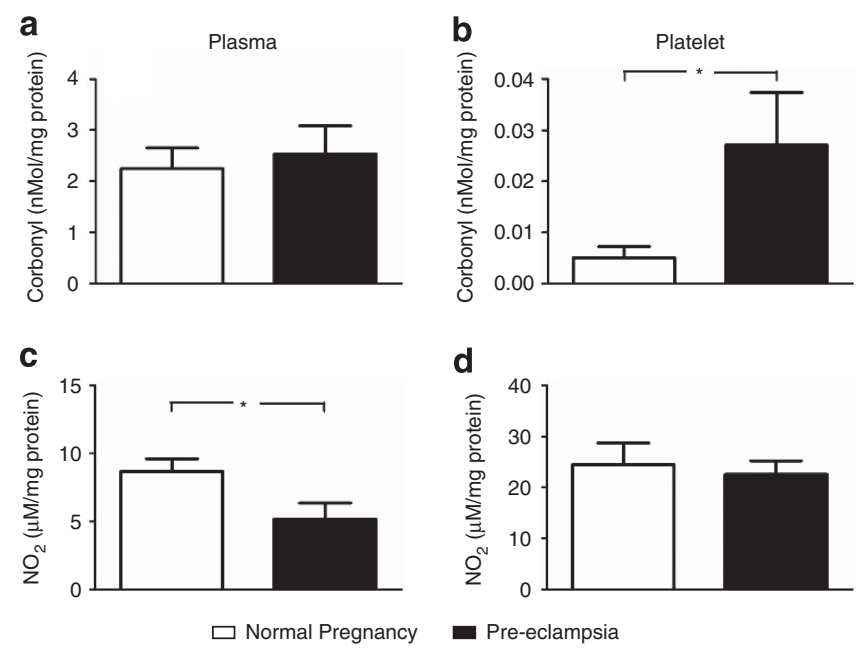

Figure 4 Carbonyl and $\mathrm{NO}_{2}$ production were analyzed in plasma and platelets from normal pregnancy (NP) and pre-eclampsia (PE) patients. Values denote means \pm s.d. of the mean $\left({ }^{*} P<0.05\right)$. (a) Plasma carbonyl $(n=4-6)$, (b) platelet carbonyl $(n=5-6)$, (c) plasma $\mathrm{NO}_{2}(n=5-6)$, (d) platelet $\mathrm{NO}_{2}(n=10)$.

with controls. A factor that could limit L-arginine transport is low plasma L-arginine levels. We assessed plasma levels of L-arginine and other amino acids to investigate metabolic changes involved in $\mathrm{PE}$, as well as to establish a correlation with PE-induced changes in amino-acid transport in platelets. However, no significant difference was observed in the levels of plasma L-arginine between the PE and control group, unlike our previous reports of diminished plasma L-arginine levels in uremic patients. ${ }^{13}$ This result is in agreement with the previous findings of Noris et al. ${ }^{26}$ and Germain et al. ${ }^{27}$ who observed no difference in plasma levels of this amino acid in PE.

Studies have shown that the exposure of membranes to ROS predisposes to lipid peroxidation, which contributes to tissue damage by promoting change in physical and structural organization of membrane components. ${ }^{28,29}$ Possibly, PE-induced changes occur in the affinity of system $\mathrm{y}^{+} \mathrm{L}$ for the substrate $\mathrm{L}$-arginine or the expression of this transporter in platelets resulting from structural changes in the membrane because of oxidative stress. This hypothesis may be reinforced by increased oxidative stress, first observed in 

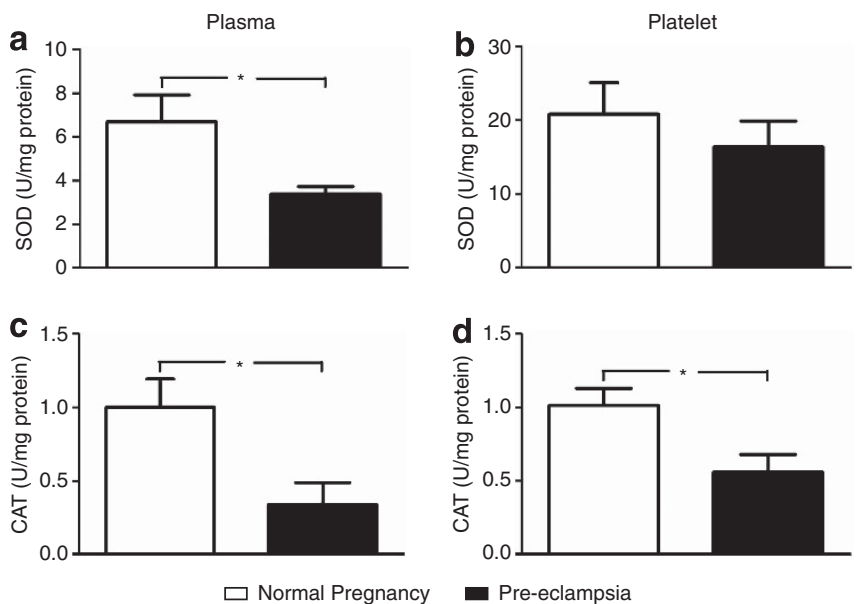

Figure 5 Superoxide dismutase (SOD) and catalase (CAT) activity were analyzed in plasma and platelets from normal pregnancy (NP) and preeclampsia (PE) patients. Values denote means \pm s.d. of the mean $\left({ }^{*} P<0.05\right)$. (a) Plasma SOD activity $(n=6-8)$, (b) platelet SOD activity $(n=8)$, (c) plasma CAT activity $(n=6)$, (d) platelet CAT activity $(n=7-10)$.

platelets of patients with PE, and be characterized by increased protein carbonyls and decreased activity of CAT, indicating a possible failure of antioxidant defense against pro-oxidant factors in PE.

Another possible mechanism is the presence of enhanced levels of L-arginine analogs, such as asymmetric dimethy-L-arginine and $\mathrm{N}^{\mathrm{G}}$-monomethyi-L-arginine, in the plasma of PE patients. Cationic $\mathrm{L}$-arginine analogs inhibit not only NOS but also L-arginine transport. Inhibition of $\mathrm{L}$-arginine transport in platelets by analogs of $\mathrm{L}$-arginine, $\mathrm{N}^{\mathrm{G}}$-monomethyi-L-arginine and asymmetric dimethyl-L-arginine is higher in hypertensive patients. ${ }^{19}$ Recent evidence has shown that plasma levels of asymmetric dimethyl-L-arginine are elevated in patients with $\mathrm{PE},{ }^{17,30}$ which reinforces our hypothesis.

The reduction of L-arginine transport in platelets by system $\mathrm{y}^{+} \mathrm{L}$ does not appear to limit the production of NO because there was no significant difference between groups in NO production, measured by the formation of $\mathrm{NO}_{2}$, and in NOS activity, measured by the conversion of $\mathrm{L}_{-}\left[{ }^{3} \mathrm{H}\right]$-arginine to $\mathrm{L}_{-}\left[{ }^{3} \mathrm{H}\right]$-citrulline in the presence of unaltered expression of iNOS and eNOS. Future studies are necessary to determine the compensatory mechanisms maintaining normal production of NO.

In this study, platelet aggregation induced by different concentrations of collagen is preserved in PE compared with control subjects. A similar result was described by Faccihinetti et al. ${ }^{14}$ and Neri et al., ${ }^{18}$ suggesting that the pregnancy itself is characterized by hyperactivity and platelet hyperaggregability without, further exacerbation occurring in PE. Although oxidative stress is observed in platelets in $\mathrm{PE}$, aggregation does not differ from normotensive patients, which can be attributed in part to an unchanged NOS activity and formation of $\mathrm{NO}_{2}$. Although we have not demonstrated that platelet aggregation induced by collagen was affected in patients with $\mathrm{PE}$, it seems reasonable to hypothesize that NO produced by platelets and/or by endothelium may be sufficient to maintain normal levels of aggregability.

The measurement of $\mathrm{NO}_{2}$ production is an indirect assay for quantifying NO production. Unlike what was observed in platelets, we demonstrated a significant reduction in the production of $\mathrm{NO}_{2}$ in the plasma of patients with PE. An inadequate modulation of NO pathway in the vasculature may be at least partially responsible for peripheral vascular resistance and elevated systemic blood pressure. These findings are in accordance with published data showing a reduction of plasma levels of $\mathrm{NO}_{2}$ and $\mathrm{NO}_{3} \cdot{ }^{16,31}$ However, increased ${ }^{32-34}$ or unchanged ${ }^{35,36}$ levels of NO were also observed, indicating discrepancy in reported findings in PE, which may be explained by differences in gestational age, maternal age and comorbidities. Finally, the reduction in antioxidant activity observed in our study could contribute to reduced levels of nitrite.

In the physiological situation, superoxide anion $\left(\mathrm{O}_{2} \bullet-\right.$, a major ROS) undergoes dismutation by SOD, but when there is a deficiency in the enzyme activity, $\mathrm{O}_{2} \bullet^{-}$can react with $\mathrm{NO}$ to generate peroxynitrite. The reaction of $\mathrm{O} 2 \bullet^{-}$with $\mathrm{NO}$ proceeds faster than with SOD. Thus, increased levels of $\mathrm{O}_{2} \bullet-$ increase peroxynitrite and decrease the availability of $\mathrm{NO}{ }^{37,38}$

The results of this study show that oxidative damage, which was assessed by protein carbonyls in plasma, was unchanged in PE. However, reduced activities of the enzymes SOD and/or CAT in plasma and platelets suggest a deficient antioxidant defense. Reduced antioxidant enzyme activity in plasma was also observed by Chamy et al. ${ }^{39}$ and Bernardi et al. ${ }^{40}$ However, measurements of oxidative damage in PE remain controversial because other studies have shown that carbonylation and lipid peroxidation can be unaltered ${ }^{2}$ or increased $^{40,41}$ compared with normal pregnancy. There is evidence of a positive correlation between the degree of oxidative damage and the severity of $\mathrm{PE},{ }^{39}$ so our findings in mild PE may be explained by the clinical feature of this group of pregnant women.

In conclusion, this study shows that a decreased plasma level of nitrite is associated with a compromised antioxidant defense, which may account, in part, for inactivation of $\mathrm{NO}$ or limited bioavailability of NO in PE. Despite normal plasma levels of L-arginine in PE, transport of $\mathrm{L}$-arginine system $\mathrm{y}^{+} \mathrm{L}$ in platelets is impaired, which may be the consequence of altered physical and structural changes of the platelet membrane caused by oxidative stress. Despite reduced Larginine transport and the increased oxidative stress in platelets from $\mathrm{PE}$, no change occurs in NOS activity, NO production or platelet aggregation. Thus, compensatory mechanisms may be contributing to the maintenance of $\mathrm{NO}$ production and its modulatory role on platelet aggregation. Further research will provide new insights into the complex physiopathology of PE.

\section{CONFLICT OF INTEREST}

The authors declare no conflict of interest.

\section{ACKNOWLEDGEMENTS}

We gratefully acknowledge the support of FAPERJ and CNPq. This work was conducted with grants from the National Council of Scientific and Technological Development (CNPq) and the Rio de Janeiro State Research Agency (FAPERJ).

1 Lorquet S, Pequeux C, Munaut C, Foidart JM. Aetiology and physiopathology of preeclampsia and related forms. Acta Clin Belg 2010; 65: 237-241.

2 Llurba E, Gratacós E, Martín-Gallán P, Cabero L, Dominguez C. A comprehensive study of oxidative stress and antioxidant status in preeclampsia and normal pregnancy. Free Radic Biol Med 2004; 37: 557-570.

3 Afzal-Ahmed I, Mann GE, Shennan AH, Poston L, Naftalin RJ. Preeclampsia inactivates glucose-6-phosphate dehydrogenase and impairs the redox status of erythrocytes and fetal endothelial cells. Free Radic Biol Med 2007; 42: 1781-1790.

4 Steinert JR, Wyatt AW, Jacob R, Mann GE. Redox modulation of $\mathrm{Ca}^{2+}$ signaling in human endothelial and smooth muscle cells in pre-eclampsia. Antiox Redox Signal 2009; 11: 1149-1163.

5 Poston L. Endothelial dysfunction in pre-eclampsia. Pharmacol Rep 2006; 58: 69-74.

6 Touyz RM, Schiffrin EL. Reactive oxygen species in vascular biology: implications in hypertension. Histochem Cell Biol 2004; 122: 339-352a. 
7 Granger JP, Alexander BT, Llinas MT, Bennett WA, Khalil RA. Pathophysioloy of preeclampsia: linking placental dysfunction. Microcirculation 2002; 9: 147-160.

8 Gilbert JS, Ryan MJ, LaMarca BB, Sedeek M, Murphy SR, Granger JP. Pathophysiology of hypertension during preeclampsia: linking placental ischemia with endothelial dysfunction. Am J Physiol Heart Circ Physiol 2008; 294: H541-H550.

9 Burton GJ, Jauniaux E. Oxidative stress. Best Pract Res Clin Obstet Gynaecol 2011 ; 25: 287-299.

10 Poston L, Igosheva N, Mistry HD, Seed PT, Shennan AH, Rana S, Karumanchi SA, Chappell LC et al. Role of oxidative stress and antioxidant supplementation in pregnancy disorders. Am J Clin Nutr 2011; 94: 1980S-1985S.

11 Bedard K, Krause KH. The NOX family of ROS-generating NADPH oxidases: physiology and pathophysiology. Physiol Rev 2007; 87: 245-313.

12 Moncada S, Higgs EA. The discovery of nitric oxide and its role in vascular biology. $\mathrm{Br} \mathrm{J}$ Pharmacol 2006; 147: 193-201.

13 Brunini TM, Mendes-Ribeiro AC, Ellory JC, Mann GE. Platelet nitric oxide synthesis in uremia and malnutrition: a role for L-arginine supplementation in vascular protection? Cardiovasc Res 2007; 73: 359-367.

14 Facchinetti F, Neri I, Piccinini F, Marietta M, Torelli U, Bruschettini PL, Volpe A et al. Effect of L-arginine load on platelet aggregation: a comparison between normotensive and preeclamptic pregnant women. Acta Obstet Gynecol Scand 1999; 78: 515-519.

15 Sibai B, Dekker G, Kupferming M. Pre-eclampsia. Lancet 2005; 4: 785-799.

16 López-Jaramillo P, Arenas WD, García RG, Rincon MY, López M. The role of the L-arginine-nitric oxide pathway in preeclampsia. Ther Adv Cardiovasc Dis 2008; 2. 261-275.

17 Böger RH, Diemert A, Schwedhelm E, Lüneburg N, Maas R, Hecher K. The role of nitric oxide synthase inhibition by asymmetric dimethylarginine in the pathophysiology of preeclampsia. Gynecol Obstet Invest 2010; 69: 1-13.

18 Neri I, Piccinini F, Marietta M, Facchinetti F, Volpe A. Platelet responsiveness to L-arginine in hypertensive disorders of pregnancy. Hypertens Pregnancy 2000; 19: 23-30.

19 Brunini T, Moss M, Siqueira M, Meirelles L, Rozentul A, Mann G et al. Inhibition of $\mathrm{L}$-arginine transport in platelets by asymmetric dimethylarginine and $\mathrm{N}$-monomethyl-Larginine: effects of arterial hypertension. Clin Exp Pharmacol Physiol 2004; 31 738-740.

20 Meirelles LR, Mendes-Ribeiro AC, Santoro MM, Mendes MA, da Silva MN, Mann GE et al. Inhibitory effects of endogenous L-arginine analogues on nitric oxide synthesis in platelets: role in platelet hyperaggregability in hypertension. Clin Exp Pharmacol Physiol 2007; 34: 1267-1271.

21 Meirelles LR, Mendes-Ribeiro AC, Mendes MA, da Silva MN, Ellory JC, Mann GE, Brunini TM et al. Chronic exercise reduces platelet activation in hypertension: upregulation of the I-arginine-nitric oxide pathway. Scand J Med Sci Sports 2009, 19: 67-74.

22 Pereira NR, Moss MB, Assumpção CR, Cardoso CB, Mann GE, Brunini TMC, Antônio C, Mendes-Ribeiro AC. Oxidative stress, L-arginine-nitric oxide and arginase pathways in platelets from adolescents with anorexia nervosa. Blood Cells Mol Dis 2010; 44 164-168

23 Moss MB, Siqueira MA, Mann GE, Brunini TM, Mendes-Ribeiro AC. Platelet aggregation in arterial hypertension: is there a nitric oxide-urea connection? Clin Exp Pharmacol Physiol 2010; 37: 167-172.
24 Green LC, Wagner DA, Glogowski J, Skipper PL, Wishnok JS, Tannenbaum SR. Analysis of nitrate, nitrite, and [15N]nitrate in biological fluids. Anal Biochem 1982; 126: 131-138.

25 Levine RL, Garland D, Oliver CN. Carbonyl assays for determination of oxidatively modified proteins. Methods Enzymol 1994; 233: 346-357.

26 Noris M, Todeschini M, Cassis P, Pasta F, Cappellini A, Bonazzola S, Macconi D, Maucci R, Porrati F, Benigni A, Picciolo C, Remuzzi G et al. L-arginine depletion in preeclampsia orients nitric oxide synthase toward oxidant species. Hypertension 2004 43: 614-622.

27 Germain AM, Romanik MC, Guerra I, Solari S, Reyes MS, Johnson RJ, Price K, Karumanchi SA, Valdés G et al. Endothelial dysfunction. A link among preeclampsia, recurrent pregnancy loss, and future cardiovascular events? Hypertension 2007; 49 90-95.

28 Jacob RF, Mason RP. Lipid peroxidation induces cholesterol domais formation in model membranes.. J Bio Chem 2005; 280: 39380-39387.

29 Halliwell B. Antioxidant defence mechanisms: from the beginning to the end (of the beginning). Free Radic Res 1999; 31: 261-272.

30 Mao D, Che J, Li K, Han S, Yue Q, Zhu L, Zhang W, Li L et al. Association of homocysteine, asymmetric dimethylarginine, and nitric oxide with preeclampsia. Arch Gynecol Obstet 2010; 282: 371-375.

31 Xiang W, Chen $\mathrm{H}, \mathrm{Xu} \mathrm{X}$, Zhang M, Jiang R. Expression of endothelial nitric oxide synthase traffic inducer in the placentas of women with pre-eclampsia. Int J Gynaecol Obstet 2005; 89: 103-107.

32 Ranta V, Viinikka L, Halmesmäki E, Ylikorkala O. Nitric oxide production with preeclampsia. Obstet Gynecol 1999; 93: 442-445.

33 Yoneyama Y, Suzuki S, Sawa R, Miura A, Doi D, Otsubo Y, Araki T et al. Plasma nitric oxide levels and the expression of P-selectin on platelets in preeclampsia. Am J Obstet Gynecol 2002; 187: 676-680.

34 Mazzanti L, Raffaelli F, Vignini A, Nanetti L, Vitali P, Boscarato V, Giannubilo SR Tranquilli $A L$ et al. Nitric oxide and peroxynitrite platelet levels in gestationa hypertension and preeclampsia. Platelets 2011; 23: 26-35.

35 Davidge ST, Signorella AP, Hubel CA, Lykins DL, Roberts JM. Distinct factors in plasma of preeclamptic women increase endothelial nitric oxide or prostacyclin. Hypertension 1996; 28: 758-764.

36 Paşaoğlu H, Bulduk G, Oğüș E, Pașaoğlu A, Onalan G. Nitric oxide, lipid peroxides, and uric acid levels in pre-eclampsia and eclampsia. Tohoku J Exp Med 2004; 202: 87-92.

37 Paravicini TM, Touyz RM. NADPH oxidases, reactive oxygen species, and hypertension: clinical implications and therapeutic possibilities. Diabetes Care 2008; 31 S170-S180.

38 Allen BW, Demchenko IT, Piantadosi CA. Two faces of nitric oxide: implications for cellular mechanisms of oxygen toxicity. J App/ Physiol 2009; 106: 662-667.

39 Chamy VM, Lepe J, Catalán A, Retamal D, Escobar JA, Madrid EM. Oxidative stress is closely related to clinical severity of pre-eclampsia. Biol Res 2006; 39: 229-236.

40 Bernardi F, Constantino L, Machado R, Petronilho F, Dal-Pizzol F. Plasma nitric oxide, endothelin-1, arginase and superoxide dismutase in pre-eclamptic women. J Obstet Gynaecol Res 2008; 34: 957-963.

41 Olsson MG, Centlow M, Rutardóttir S, Stenfors I, Larsson J, Hosseini-Maaf B, Olsson ML, Hansson SR, Akerström B et al. Increased levels of cell-free hemoglobin, oxidation markers, and the antioxidative heme scavenger alpha(1)-microglobulin in preeclampsia. Free Radic Biol Med 2010; 48: 284-291. 